\title{
Sexual Dysfunction in HIV-Positive Women Attending a Tertiary Health Facility in North Central Nigeria
}

\author{
Ayo Oyedokun ${ }^{*}$, Loius Okeibunor Odeigah, Kola Moradeyo Alabi, Olushola Abejide Adegunloye and Henry Chukwuma Akujobi \\ St. Nicholas Hospital, LAGOS, Nigeria
}

Corresponding author:Ayo Oyedokun, St. Nicholas Hospital, Lagos, Nigeria, Tel: 08022241686; E-mail:ayooyedokun@yahoo.com

Received date: October 18, 2014; Accepted date: November 27, 2014; Published date: December 02, 2014

Copyright: (C) 2014 Oyedokun A, et al. This is an open-access article distributed under the terms of the Creative Commons Attribution License, which permits unrestricted use, distribution, and reproduction in any medium, provided the original author and source are credited.

\begin{abstract}
Introduction: Sexual dysfunction in HIV positive women is highly prevalent and it is often associated with psychosocial distress. Not much scientific attention has been dedicated to this important aspect of the life of the HIVpositive woman especially in Nigeria and in the West African sub region at large, where issues pertaining to sexuality are hardly ever discussed even in routine clinic visits due to cultural restrictions.
\end{abstract}

Objectives: To determine the prevalence, psychological status, and socio demographic/clinical factors associated with sexual dysfunction in HIV-positive women.

Methods: This was a hospital based cross-sectional study conducted over six months. Data were collected from 370 respondents using a structured questionnaire. The General Health Questionnaire (GHQ12) was used to assess their psychological status while the modified Female Sexual Function Index Questionnaire (FSFI) was used to assess female sexual dysfunction. Questionnaire was interviewer administered by and the data was analysed using Epi-info 2011 package.

Results: It showed that the prevalence of Sexual Dysfunction in HIV positive women was sixty one (61\%). Thirty five $(35 \%)$ of the respondents had significant psychological distress. The presence of psychological distress was significantly associated with Female Sexual Dysfunction (FSD). There was no association between FSD and religion, ethnicity, duration of marriage or presence of other chronic diseases. Increasing age, multiple sex partners, non-disclosure of HIV status, stigma, on-going stressful event, being underweight or obese were significantly associated with FSD. High level of education, being married, monogamy, WHO clinical stage I disease and higher CD4 count were associated with better sexual functioning.

Conclusion: This study brings to the fore the need for physicians and healthcare workers who render comprehensive care as frontline doctors to acquire skills that is needed to attend to and alleviate the sexual problems of women in an African setting.

Keywords: Sexual dysfunction; HIV-positive; Women

\section{Introduction}

Sexual dysfunction is a group of disorders associated with desire, arousal, orgasm problems and painful sexual intercourse (dyspareunia and vaginismus) [1]. It refers to a person's inability to "participate in a sexual relationship as he or she would wish." This dysfunction is expressed in various ways: a lack of desire or of pleasure or of physiological inability to begin, maintain, or complete sexual interaction [2]. The essential feature of the sexual dysfunctions is inhibition on one or more of these phases including disturbance in the subjective sense of pleasure or in the objective performance [3]. Sexual Dysfunction in women encompasses persistent or recurrent disorders of sexual interest/desire, disorders of subjective and genital arousal, orgasm disorder, pain, and difficulty with attempted or completed intercourse [4]

Research on the effects of HIV infection on sexual functioning in women is of particular interest because of its implications for a variety of issues including: prevention of HIV transmission to partners or future offspring; understanding how fear of transmitting the virus affects sexual enjoyment; anticipating pre-and post- diagnosis changes in sexual and relationship functioning; partner notification; communication between partners concerning contraception and safer sex practices; identification of factors that may contribute to sexual difficulties in HIV infected women (e.g. social or economic deprivation, depression, etc.); and provision of effective treatment, support, or other interventions to address such difficulties and related concerns [5].

Although data suggest that women with HIV are at particular risk of developing sexual problems [6], Epidemiological investigations of women with sexual dysfunctions from well-designed randomlysampled community-based population are limited [1]. More so, little is known on Female Sexual Dysfunction (FSD) among HIV-positive women especially in Africa [7].

Before the introduction of Highly Active Anti-retroviral Therapy (HAART), sexual dysfunction was commonly reported in HIVinfected persons with advanced disease and was attributed to opportunistic infections, debilitating illness, and altered general health status. In the last few years, despite the enormous advantage of HAART in terms of improved general physical and psychological well- 
being, some reports have documented an increased occurrence of sexual dysfunction among patients treated with HAART [8]. Even if its ethology is still controversial, several factors may contribute to sexual dysfunction in HIV-infected persons: psychological and emotional issues, endocrine alterations, peripheral and autonomic neuropathy, as well as side effects of antiretroviral therapy or of other medications used to treat opportunistic infections. Moreover, it is possible that, as a result of effective therapies, patients who are living longer and feeling better now bring into focus the issue of sexual satisfaction [8].

Women's self-esteem, body image, their relationship with their partners, and their ability to communicate their sexual needs with their partner are among the issues that impact their sexual function $[9,10]$.

\section{Materials and Methods}

This study was approved by the Ethical Review Committee of the University of Ilorin Teaching hospital. It was a hospital based crosssectional descriptive study which was conducted over a six month (26 weeks) period between $7^{\text {th }}$ of December 2011 and $7^{\text {th }}$ of June 2012. The study was carried out at the Lentiviral Clinic of the Department of Family Medicine, University of Ilorin Teaching Hospital Ilorin (UITH), Kwara state, Nigeria. Ilorin is the capital of Kwara State in the North Central geopolitical zone of Nigeria. All adult female HIVpositive patients who were 18 years and above, accessing care, treatment and support at the Family medicine lentiviral clinic of UITH who were willing to participate and gave a written informed consent were included. Patients who were on treatment for pulmonary tuberculosis during this period were excluded. Patients who were very ill and required admission were also excluded.

The required sample size was determined using Fischer's statistical formula for estimating minimum sample size in health studies [11].

$$
\mathrm{n}=\mathrm{Z}^{2} \mathrm{pq}
$$$$
\mathrm{d}^{2}
$$

\section{Where $\mathrm{n}=$ desired sample size}

$\mathrm{Z}=$ standard normal deviation, usually set at 1.96 which corresponds to $95 \%$ confidence level.

$\mathrm{p}=$ proportion in the target population estimated to have a particular characteristics.

A prevalence of sexual dysfunction in HIV infected women of about $32 \%$ reported in a previous study was used.

Therefore, $\mathrm{p}=0.32$

$\mathrm{q}=1-\mathrm{p}=0.68$

$\mathrm{d}=$ degree of accuracy desired usually set at 0.05 . Therefore the sample size for this study was:

$$
\mathrm{n}=(1.96)^{2}(0.32)(0.68)
$$

$\mathrm{n}=334.37$

An attrition rate of $10 \%$ was envisaged for non-respondents and poorly completed questionnaires. This percentage was added to the calculated sample size to arrive at 367.8. An approximate sample size of 370 was therefore used for the study.
The Psychological status of the respondents was assessed with the General Health Questionnaire (GHQ 12) which consists of a total of 12 items developed by Goldberg [12]. This study made use of Goldberg's original scoring method. In this method response categories score $0,0,1$, and 1 respectively. This gives scores ranging from 0 to 12 [12]. The English and Yoruba-translated versions had been validated in Nigeria, with a cut-off score of 3-and-above indicating presence of clinically significant psychopathology $[13,14]$.

The Female Sexual Function Index (FSFI) was used to assess sexual functioning. It is a 19-item questionnaire. It was developed as a brief, multidimensional self-report instrument for assessing the key dimensions of sexual function in women. It is assigned to six separate domains which include desire disorder, arousal, lubrication, orgasm, satisfaction, and pain. The individual domain scores are obtained by adding the scores of the individual items that comprise the domain and multiplying the sum by the domain factor. The maximum score for each domain is six and a full scale score was obtained by adding the six domain scores. The maximum score is 36 and the minimum score is 2. A FSFI score of below 26.55 is deemed poor and suggests sexual dysfunction $[15,16]$. The FSFI was modified to assess sexual functioning in the past six months as against 4 weeks in the original version. This is to make provision for our culture and environment where polygamy and related issues may not allow the HIV-positive woman sexual access to her partner as frequently as expected.

Other parameters obtained from each respondent were the medical and social history, weight, height and a recent CD4 count. The data was analysed using the epidemiological information (Epi-info) 2011 software package version 3.5.3. Frequency tables were generated and the chi-square test was used in assessing the significance of associations between categorical groups. P-values less than 0.05 were regarded as statistically significant. Data presentation formats like pie charts, and bar charts were drawn using Excel 2003 software package.

\section{Results}

A total of 370 eligible consenting HIV positive women were recruited for this study. The age range of the respondents was between 20 and 69 years. The mean age was $38 \pm 9.4$ years. The most predominant religion was Islam (53.0\%). More of the patients had post-secondary education (35.4\%). Business/trading was the most common occupation $(52.2 \%)$ while students were the least in number (2.4\%). Majority of respondents were of the Yoruba ethnic group (77\%).

\begin{tabular}{|l|l|l|}
\hline Sociodemographic data $(\mathbf{n = 3 7 0 )}$ & Frequency & (\%) \\
\hline Age (years) & 50 & $(13.5)$ \\
\hline $20-29$ & 180 & $(48.7)$ \\
\hline $30-39$ & 97 & $(26.2)$ \\
\hline $40-49$ & 30 & $(8.1)$ \\
\hline $50-59$ & 13 & $(3.5)$ \\
\hline$\geq 60$ & \multicolumn{2}{|l}{} \\
\hline Religion & 174 & $(47.0)$ \\
\hline Christianity & 196 & $(53.0)$ \\
\hline Islam & \multicolumn{2}{|l|}{} \\
\hline
\end{tabular}




\begin{tabular}{|c|c|c|}
\hline \multicolumn{3}{|l|}{ Educational Level } \\
\hline No formal education & 100 & $(27.0)$ \\
\hline Primary & 51 & (13.8) \\
\hline Secondary & 88 & $(23.8)$ \\
\hline Tertiary & 131 & $(35.4)$ \\
\hline \multicolumn{3}{|l|}{ Occupation } \\
\hline Artisans & 32 & $(8.7)$ \\
\hline Business/Trading & 193 & $(52.2)$ \\
\hline civil servant & 93 & $(25.1)$ \\
\hline Students & 9 & $(2.4)$ \\
\hline Unemployed & 43 & (11.6) \\
\hline \multicolumn{3}{|l|}{ Ethnicity } \\
\hline Yoruba & 285 & $(77.0)$ \\
\hline Hausa & 30 & $(8.1)$ \\
\hline Igbo & 19 & $(5.2)$ \\
\hline Others & 36 & $(9.7)$ \\
\hline
\end{tabular}

Table 1: Socio-demographic Characteristics of Respondents. Mean \pm SD Age $=38 \pm 9.4$ years

The prevalence of Sexual Dysfunction in HIV positive women from this study was sixty one (61\%). Thirty five $(35 \%)$ of the respondents had significant psychological distress. The presence of psychological distress was significantly associated with Female Sexual Dysfunction (FSD). There was no association between FSD and religion, ethnicity, duration of marriage or presence of other chronic diseases. Increasing age, multiple sex partners, non-disclosure of HIV status, stigma, ongoing stressful event, being underweight or obese were significantly associated with FSD. High level of education, being married, monogamy, WHO clinical stage I disease and higher $\mathrm{CD}_{4}$ count were associated with better sexual functioning. The most prevalent type of sexual dysfunction was found in the domain of Desire (88.4\%) while the least was in the domain of Pain (41.6\%).

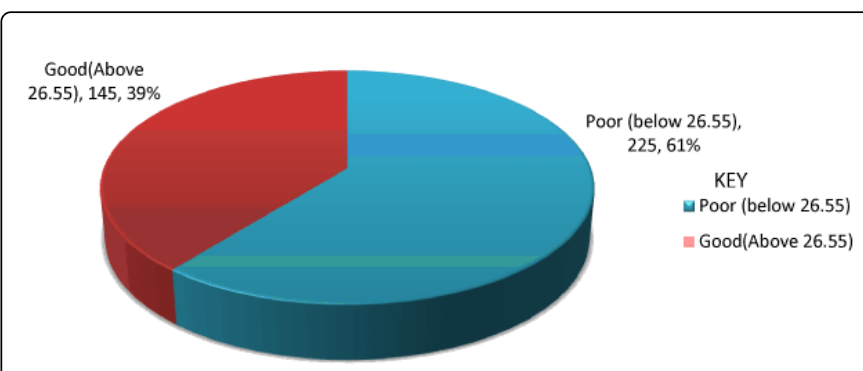

Figure 1: Prevalence of Sexual Dysfunction Among HIV-Positive Women. Illustrates the total number of the respondents with sexual dysfunction. It shows an overall prevalence of $61 \%$ for female sexual dysfunction in HIV positive women.

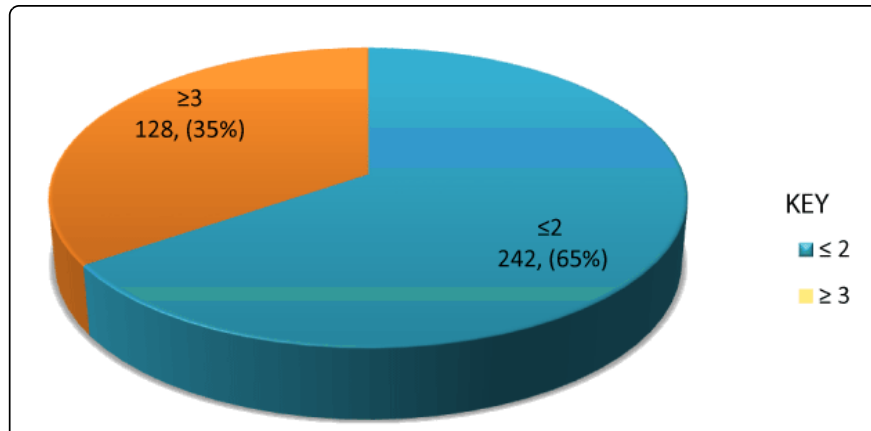

Figure 2: Psychological Status of the HIV-Positive Women. Illustrates the psychological status of the HIV positive women. 35\% of the respondents had a GHQ score of 3 and above which signifies significant psychopathology.

\begin{tabular}{|l|l|l|l|l|l|l|}
\hline & \multicolumn{5}{|l|}{ Female Sexual Dysfunction } \\
\hline $\begin{array}{l}\text { General } \\
\text { Health } \\
\text { Questionnaire } \\
\text { Score }\end{array}$ & ABSENT & PRESENT & Total & $\mathbf{X}^{2}$ & df & P-value \\
\hline Good & $\begin{array}{l}119 \\
(49.2)\end{array}$ & $123(50.8)$ & $242(100.0)$ & & & \\
\hline Poor & $26(20.3)$ & $102(79.7)$ & $128(100.0)$ & 29.26 & 1 & 0.0000 \\
\hline Total & $145(39.2)$ & $225(60.8)$ & $370(100.0)$ & & & \\
\hline
\end{tabular}

Table 2: Association between Psychological Status of Respondents and Female Sexual Dysfunction.

Table 2 shows the relationship between the psychological status of respondents and female sexual dysfunction. Respondents with significant psychopathology had a higher incidence of FSD (79.7\%) when compared with those without psychopathology (50.8\%). This relationship was statistically significant.

\begin{tabular}{|c|c|c|c|c|c|c|}
\hline $\begin{array}{l}\text { Socio- } \\
\text { demograph } \\
\text { ic data }\end{array}$ & \begin{tabular}{|l|} 
HIV \\
Positive \\
with no \\
FSD \\
$\mathrm{N}=145$ \\
$(39.2)$
\end{tabular} & $\begin{array}{l}\text { HIV } \\
\text { Positive } \\
\text { with FSD } \\
\mathrm{N}=225 \\
(60.8)\end{array}$ & $\begin{array}{l}\text { Total } \\
\mathrm{N}=370 \\
(100.0)\end{array}$ & $x^{2}$ & df & P-value \\
\hline \multicolumn{7}{|l|}{ Age (years) } \\
\hline $20-29$ & $27(54.0)$ & $23(46.0)$ & $50(100.0)$ & & & \\
\hline 30-39 & $81(45.0)$ & $99(55.0)$ & $180(100.0)$ & & & \\
\hline $40-49$ & $27(27.8)$ & $70(72.2)$ & $97(100.0)$ & 19.37 & 4 & 0.0006 \\
\hline $50-59$ & $7(23.3)$ & $23(76.7)$ & $30(100.0)$ & & & \\
\hline$\geq 60$ & $3(39.2)$ & $10(60.8)$ & $13(100.0)$ & & & \\
\hline \multicolumn{7}{|l|}{ Religion } \\
\hline Christianity & $69(39.7)$ & $105(60.3)$ & $174(100.0)$ & & & \\
\hline Islam & $76(38.8)$ & $120(61.2)$ & $196(100.0)$ & 0.029 & 1 & 0.8626 \\
\hline
\end{tabular}


Citation: Oyedokun A, Odeigah LO, Alabi KM, Adegunloye OA, Akujobi HC (2014) Sexual Dysfunction in HIV-Positive Women Attending a

Page 4 of 5

\begin{tabular}{|c|c|c|c|c|c|c|}
\hline $\begin{array}{l}\text { No formal } \\
\text { education }\end{array}$ & $29(29.0)$ & $71(71.0)$ & $100(100.0)$ & & & \\
\hline Primary & $17(33.3)$ & $34(66.7)$ & $51(100.0)$ & & & \\
\hline Secondary & $36(40.9)$ & $52(59.1)$ & $88(100.0)$ & 9.56 & 3 & 0.0227 \\
\hline Tertiary & $63(48.1)$ & 68 (51.9) & $131(100.0)$ & & & \\
\hline \multicolumn{7}{|l|}{ Occupation } \\
\hline Artisans & $11(34.4)$ & $21(65.6)$ & $32(100.0)$ & & & \\
\hline $\begin{array}{l}\text { Business/ } \\
\text { Trading }\end{array}$ & $65(33.7)$ & $128(66.3)$ & $193(100.0)$ & & & \\
\hline civil servant & 59 (63.4) & 34 (36.6) & $93(100.0)$ & 34.45 & 4 & 0.0000 \\
\hline Student & $2(22.2)$ & $7(77.8)$ & $9(100.0)$ & & & \\
\hline $\begin{array}{l}\text { Unemploye } \\
\text { d }\end{array}$ & $8(18.6)$ & $35(81.4)$ & $43(100.0)$ & & & \\
\hline \multicolumn{7}{|l|}{ Ethnicity } \\
\hline Yoruba & 113 (39.6) & $172(60.4)$ & $285(100.0)$ & & & \\
\hline Hausa & $9(30.0)$ & $21(70.0)$ & $30(100.0)$ & 4.39 & 3 & 0.2218 \\
\hline Igbo & 11 (57.9) & $8(42.1)$ & $19(100.0)$ & & & \\
\hline Others & $12(33.3)$ & $24(66.7)$ & $36(100.0)$ & & & \\
\hline
\end{tabular}

Table 3: Socio-demographic variables of the respondents with sexual dysfunction compared with those without sexual dysfunction.

Table 3 shows socio-demographic variables of respondents with Female sexual dysfunction (FSD). FSD was higher in the age group $\geq 60$ years and least among the $20-29$. This was statistically significant $\left(\mathrm{p}=0.0006, \mathrm{x}^{2}=19.37\right)$. FSD was least among those with post-secondary education $(51.9 \%)$. This was also statistically significant $(\mathrm{p}=0.0227$, $\left.\mathrm{x}^{2}=9.56\right)$. FSD was more among the unemployed respondents $(81.4 \%)$. FSD was also more among the Hausa tribe and least among the Igbo, this was however not statistically significant.

\begin{tabular}{|c|c|c|c|c|c|c|}
\hline $\begin{array}{l}\text { Clinical } \\
\text { parameters }\end{array}$ & $\begin{array}{l}\text { Good } \\
\text { n (145\%) }\end{array}$ & $\begin{array}{l}\text { Poor } \\
n \quad(225 \\
(60.8)\end{array}$ & $\begin{array}{l}\text { Total } \\
n \begin{array}{l}n \\
100.0)\end{array}\end{array}$ & $\mathbf{X} 2$ & Df & P-value \\
\hline \multicolumn{7}{|l|}{ Present BMI } \\
\hline Underweight & $3(16.7)$ & $15(83.3)$ & $18(100)$ & & & \\
\hline Normal & $94(45.2)$ & $114(54.8)$ & $208(100.0)$ & & & \\
\hline Overweight & $41(39.4)$ & $63(60.6)$ & $104(100)$ & 14.88 & 3 & 0.0019 \\
\hline Obese & $7(17.5)$ & $33(82.5)$ & $40(100.0)$ & & & \\
\hline Total & $145(39.2)$ & $225(60.8)$ & $370(100.0)$ & & & \\
\hline \multicolumn{7}{|c|}{$\begin{array}{ll}\text { Year } & \text { of } \\
\text { diagnosis } & \end{array}$} \\
\hline$<1$ years & $6(24.0)$ & $19(76.0)$ & $25(100.0)$ & & & \\
\hline 1-5years & $131(41.6)$ & $184(58.4)$ & $315(100.0)$ & 5.15 & 2 & 0.0760 \\
\hline$>5$ year & $8(26.7)$ & $22(73.3)$ & $30(100.0)$ & & & \\
\hline Total & & & & & & \\
\hline
\end{tabular}

\begin{tabular}{|l|l|l|l|l|l|l|}
\hline \multicolumn{6}{|l|}{ WHO Clinical Stage of disease } \\
\hline Stage I & $90(45.7)$ & $107(54.3)$ & $197(100.0)$ & & & \\
\hline Stage II & $52(35.9)$ & $93(64.1)$ & $145(100.0)$ & 13.69 & 2 & 0.0011 \\
\hline Stage III & $3(10.7)$ & $25(89.3)$ & $28(100.0)$ & & & \\
\hline Year HAART was commenced & $9(33.3)$ & $18(66.7)$ & $27(100.0)$ & & & \\
\hline$<$ 1years & $127(43.3)$ & $166(56.7)$ & $293(100.0)$ & & & \\
\hline 1-5years & $4(16.0)$ & $21(84.0)$ & $25(100.0)$ & 7.78 & 2 & 0.0204 \\
\hline$>5$ year & $140(40.6)$ & $205(59.4)$ & $345(100.0)$ & & & \\
\hline Total & $0(0.0)$ & $2(100.0)$ & $2(100.0)$ & & & \\
\hline HAART & $99(38.8)$ & $156(61.2)$ & $255(100.0)$ & & & \\
\hline alluvia/truvada & 0 & & & & \\
\hline Combipak & $29(39.2)$ & $45(60.8)$ & $74(100.0)$ & & & \\
\hline truv/nvp & $8(66.7)$ & $4(33.3)$ & $12(100.0)$ & & & \\
\hline Truvada/EFV & $0(0.0)$ & $2(100.0)$ & $2(100.0)$ & 6.500 & 5 & 0.2605 \\
\hline Zdv, 3TC,EFV & $08(31.1)$ & $62(68.9)$ & $90(100.0)$ & & & \\
\hline yet to start & $9(36.0)$ & $16(64.0)$ & $25(100.0)$ & & & \\
\hline Total & $145(39.2)$ & $225(60.8)$ & $370(100.0)$ & & & \\
\hline $\begin{array}{l}\text { PRESENT CD4 } \\
\text { <200 }\end{array}$ & $8(9.8)$ & $74(90.2)$ & $82(100.2)$ & & & \\
\hline $200-349$ & $48(51.6)$ & $45(48.4)$ & $93(100.0)$ & 22.21 & 2 & 0.00002 \\
\hline $350-499$ & $61(58.1)$ & $44(41.9)$ & $105(100.0)$ & & & \\
\hline$\geq 500$ & $145(39.2)$ & $225(60.8)$ & $370(100.0)$ & & & \\
\hline Total & & & & & & \\
\hline
\end{tabular}

Table 4: Clinical Parameters of the Respondents with Sexual Dysfunction Compared with those without Sexual Dysfunction.

Table 4 shows the relationship between clinical parameters and Female sexual Dysfunction (FSD). FSD occurred more among respondents who were underweight $(83.3 \%)$ and obese $(82.5 \%)$ than in normal $(54.8 \%)$ and overweight $(60.6 \%)$, This was statistically significant. FSD occurred more in WHO clinical stage III (89.3\%) than in stages I (54.3\%) and II (64.1\%). FSD occurred more in respondents who used ALLUVIA/TRUVADA than other drug combinations. This was not statistically significant. FSD occurred more among patients with present CD4 count of 200 (90.2\%) and least in those with CD4 count above 500 (41.9\%). This was statistically significant $(\mathrm{P}=0.00002$, $\mathrm{X}^{2}=22.21$ ).

\section{Discussion}

The prevalence of sexual dysfunction in HIV positive women was considerably higher than what was reported by Luzi et al. [10] in Brazil who reported a prevalence of $32 \%$. The difference may be because of cultural differences in the setting of the study or due to the fact that African women generally avoid talking openly about sex and hence do not seek solution for their sexual concerns. Although no study in 
Nigeria on Female Sexual dysfunction specifically in HIV infected women was found, Fajewonyomi et al. [1] found a prevalence of $63 \%$ among females of reproductive age in a hospital setting in ile-ife, south west Nigeria. This is comparable with findings from this study. Ogbera et al. [4] found a FSD prevalence of $80 \%$ in diabetic women studied in Lagos, Nigeria. These bring to the fore the need for family physicians to get detailed sexual history from their patients especially those with chronic illnesses. More studies on Female sexual dysfunction in HIVpositive women in Nigeria are therefore necessary.

Psychosocial problems are major concerns which negatively affect the sexual functioning of women with HIV. This study further showed that $79.7 \%$ of those with psychosocial morbidity (GHQ score of 3 and above) had sexual dysfunction as against $50.8 \%$ in those who had no psychosocial morbidity. This relationship was found to be statistically significant. This agrees with a study by Schrooten et al. [7] which suggests that Sexual dysfunction in women with HIV infection is frequent and is mainly driven by psychological factors and by the HIV diagnosis.

This study noted that only $35.4 \%$ of respondents have postsecondary (tertiary) education. It can therefore be said that most of the participants had low level of education. This could affect the ability of the participants to fully understand and participate rationally in the study. However, the translation of the questionnaires to the local language of Yoruba together with the fact that it was administered to each participant by the researchers in a convenient and confidential environment made all participants comfortable enough to participate. FSD in the respondents was less in those who had post-secondary education and was worse among those with no formal education. This is so probably because educated women may have a better understanding of the disease and worry less about being HIV positive than those who are less educated who may even ascribe the disease to witchcraft or magical spells on them. More educated women are also generally more confident and have more access to discuss issues relating to sex and sexuality [1]. Access to information through the internet, electronic or print media is also an advantage for the educated women.

Although not statistically significant, Female Sexual Dysfunction was found to be more among the respondents who were of the Hausa tribe. This is probably related to high level of polygamous practice among the Hausas $[17,18]$. Polygamy and increasing number of wives were also found to be related to sexual dysfunction in the respondents, this may be because in a polygamous family setting, the woman may not have access to her husband/partner as much as she desires.

\section{Conclusion}

From this study, it can be concluded that sexual dysfunction is highly prevalent in HIV positive women. It is mostly associated with psychological problems, problems with relationships and stigma. There is paucity of research that has been done in Nigeria on this subject matter which might be because issues pertaining to sexuality are not freely discussed in our environment especially by women. It was however observed from this study that given the right atmosphere of confidentiality and trust, most women will freely discuss their sexual problems with their physicians.
This study will help primary care physicians to appreciate the magnitude of the burden of Female sexual dysfunction, its correlates and stir up further research activities in this regard.

\section{References}

1. Fajewonyomi BA, Orji EO, Adeyemo AO (2007) Sexual dysfunction among female patients of reproductive age in a hospital setting in Nigeria. J Health Popul Nutr 25: 101-106.

2. (2013) International statistical classification of diseases and related health problems (ICD-10). (10th edn), Lippincott William \& wilkins publishers 1034-1041.

3. Sadock BJ, Sadock VA (2003) Neuropsychiatric Aspects of HIV Infection and AIDS. Lippincott William \&wilkins publishers 1034-1041.

4. Ogbera AO, Chinenye S, Akinlade A, Eregie A, Awobusuyi J (2009) Frequency and correlates of sexual dysfunction in women with diabetes mellitus. J Sex Med 6: 3401-3406.

5. Denis A, Hong S (2003) Sexual functioning of women with HIV: a comparison with non-HIV women. Canadian Journal of Human Sexuality.

6. Bell C, Richardson D, Wall M, Goldmeier D (2006) HIV-associated female sexual dysfunction - clinical experience and literature review. Int J STD AIDS 17: 706-709.

7. Florence E, Schrooten W, Dreezen C, Gordillo V, Nilsson Schönnesson L, et al. (2004) Prevalence and factors associated with sexual dysfunction among HIV-positive women in Europe. AIDS Care 16: 550-557.

8. Trotta MP, Ammassari A, Murri R, Marconi P, Zaccarelli M, et al. (2008) Self-reported sexual dysfunction is frequent among HIV-infected persons and is associated with suboptimal adherence to antiretrovirals. AIDS Patient Care STDS 22: 291-299.

9. Trotta MP, Ammassari A, Murri R, Marconi P, Zaccarelli M, et al. (2008) Self-reported sexual dysfunction is frequent among HIV-infected persons and is associated with suboptimal adherence to antiretrovirals. AIDS Patient Care STDS 22: 291-299.

10. Ishak IH, Low WY, Othman S (2010) Prevalence, risk factors, and predictors of female sexual dysfunction in a primary care setting: a survey finding. J Sex Med 7: 3080-3087.

11. Luzi K, Guaraldi G, Murri R, De Paola M, Orlando G, et al. (2009) Body image is a major determinant of sexual dysfunction in stable HIVinfected women. Antivir Ther 14: 85-92.

12. Araoye MO (2004) Sample Size Determination in Research methodology with statistics for health and social sciences. Nathadex publishers 15-20.

13. Goldberg D (1992) General Health Questionnaire (GHQ-12) Windsor, NFER-Nelson, UK.

14. Abiodun OA (1994) A validity study of the Hospital Anxiety and Depression Scale in general hospital units and a community sample in Nigeria. Br J Psychiatry 165: 669-672.

15. Gureje O (1991) Reliability and the factor structure of the Yoruba version of the 12-item General Health Questionnaire. ActaPsychiatrScand 84: $125-129$.

16. Echeverry MC, Arango A, Castro B, Raigosa G (2010) Study of the prevalence of female sexual dysfunction in sexually active women 18 to 40 years of age in Medellín, Colombia. J Sex Med 7: 2663-2669.

17. Wiegel M, Meston C, Rosen R (2005) The female sexual function index (FSFI): cross-validation and development of clinical cutoff scores. J Sex Marital Ther 31: 1-20.

18. Halperin DT, Epstein H (2004) Concurrent sexual partnerships help to explain Africa's high HIV prevalence: implications for prevention. Lancet 364: 4-6. 